\title{
The use of comparative yield and dry-weight-rank tech- niques for monitoring arid rangeland
}

\author{
M.H. FRIEDEL, V.H. CHEWINGS, AND G.N. BASTIN
}

\section{Abstract}

The comparative yield (CY) method for estimating pasture dry weight and the dry-weight-rank (DWR) method for determining species composition were applied in a variety of arid vegetation types by several operators. The methods were evaluated for their suitability in a range monitoring program, on the basis of consistency of estimates and the time taken. Four calibration regressions for the CY technique were compared initially and; of these, linear regression of untransformed data is recommended. Differences among operators' yield estimates were unacceptably large, and the procedure of standard selection and calibration was too slow. We suggest that photographic standards can reduce the time taken and improve precision. The DWR technique was recommended because operators achieved consistent estimates of species composition within 80 minutes, which we regarded as a reasonable time for a monitoring procedure. Weighted multipliers did not improve composition estimates. The technique was easy to use but initial training of operators was important. While fixed quadrats would probably reduce differences caused by spatial variability, time spent relocating quadrats could be excessive.

Key Words: pasture yield, composition, consistency, time

Methods for determining herbage species composition and yield are basic requirements for interpreting seasonal and management effects in most native pastures. For the purposes of range monitoring, methods need to be rapid and capable of sampling adequately across the spatial heterogeneity in vegetation distribution. Methods must also be effective regardless of seasonal conditions, and different operators should be able to use them consistently.

There have been many studies of particular methods (e.g., van Dyne et al. 1963, Bonham 1976, Santillan et al. 1979, Strauss and Neal 1983), usually focussing on the size, shape, or number of sampling units. In general they have not compared the performance of several operators with the same technique. Fewer studies have investigated the comparative performance of several methods at once (Hyder and Sneva 1960, Walker 1970, Poissonet et al. 1973, Reese et al. 1980). This may not be an important consideration in relatively uniform, high yielding vegetation; but, in arid and semiarid rangelands where vegetation is sparse and very unevenly distributed, some commonly used methods fail.

Working in the arid rangelands of central Australia, Friedel and Shaw (1987) compared several operators using 3 techniques for pasture cover or yield and 4 for pasture composition. The techniques were: aerial cover with a wheelpoint apparatus, yield from quadrat clipping, and yield from whole-site estimation after clipping; pasture composition was estimation with the same techniques and with frequency quadrats. No technique was found in which operator differences were reduced to acceptable levels within realistic time limits. Using single operators was essential, to minimize errors. With this proviso, the wheelpoint method for aerial cover and composition was the best of the methods tested. It

\footnotetext{
Authors are senior research scientist and experimental scientist, Division of Wildlife and Ecology, CSIRO, P.O. Box 2111, Alice Springs, Northern Territory, Australia; and range management agronomist, Department of Primary Production, Alice Springs, Northern Territory, Australia.

Authors wish to thank G. Pearce, B. Strong, D. Nelson and A. Nelson for field assistance, and G. Griffin for statistical advice. The support of K. Masters was invaluable throughout. We particularly appreciate the help and interest of the Purvis family at Atartinga.

Manuscript accepted 7 June 1988.
}

was, however, a difficult technique to use in shrubby areas and consequently impractical for lengthy use in a monitoring program.

Since there were no published reports of a satisfactory method for estimating pasture amount and composition in extensively managed arid rangelands, studies were extended to 2 complementary techniques. The dry-weight-rank (DWR) method for species composition was devised by 't Mannetje and Haydock (1963) for tropical pastures and improved by Jones and Hargreaves (1979). Statistical tests have demonstrasted its robustness (Sandland et al. 1982) and it has been widely applied (Tothill et al. 1978, Kelly and McNeill 1980, Barnes et al. 1982, Gillen and Smith 1986). The comparative yield (CY) estimation of pasture dry weight (Haydock and Shaw 1975) could be readily combined with the DWR estimation of species composition (Tothill et al. 1978, Kelly and McNeill 1980). Both procedures were potentially useful because they were rapid, but no tests had been reported for arid environments.

The study examines the value of CY and DWR methods, by determining the extent of among-operator differences in a range of arid vegetation types. Available time is generally a limiting factor in range monitoring procedures, and staff turnover in monitoring agencies is such that repeated assessments are likely to be made by different operators. Methods must enable us to rapidly estimate yield and composition, and to detect change from one occasion to the next, despite a change in operator. While consistency from one occasion to the next is important for a single operator, we perceive that consistency among different operators is a more critical problem.

In addition, the accuracy of a yield estimate (that is, its proximity to the actual yield of a site) is not readily determined without harvesting the greater part of the site. Actual yield can vary markedly in a limited area and in a short time, so that its accurate determination is neither feasible nor necessary. We assume that precision is more important, so that, with different operators, a reasonably consistent estimate of current yield is achieved, and change over extended time can be detected. Consequently, we do not attempt to compare estimates with actual values.

Vegetation types were chosen for their different spatial distributions of pasture and for contrasting structure and composition. The tests were not repeated over time. Other estimates of yield and composition were not compared but the tests were planned to enable comparison with the earlier study by Friedel and Shaw (1987).

\section{Methods}

The experimental area was located on Atartinga Station $\left(22^{\circ} 26^{\prime} \mathrm{S}\right.$, $\left.134^{\circ} 14^{\prime} \mathrm{E}\right), 150 \mathrm{~km}$ north-north-east of Alice Springs, in the 250 $\mathrm{mm}$ annual rainfall zone of the Northern Territory of Australia. The area experiences hot summers and cool winters, and on average over $70 \%$ of the rain falls in the summer months, October to March. At the time of the study, July 1985, the preceding summer had been dry and there had been no effective winter rain.

Five sites were selected in range types preferred by grazing cattle (Table 1), and varied from 2 to $9 \mathrm{ha}$, depending on the area available. The sites differed from one another in pasture composition and yield and in the spatial distribution of vegetation.

The methods to be tested depended on dry weights of plant material and so, in a preparatory exercise, a wide variety of pasture 
Table 1. Landform, soil and vezetation description of 5 experimental sites. Soll descriptions follow Northeote (1971).

\begin{tabular}{|c|c|c|}
\hline Range type & Landform and soils & Vegetation \\
\hline $\begin{array}{l}\text { Calcareous } \\
\text { shrubby grass- } \\
\text { land (CSG) }\end{array}$ & $\begin{array}{l}\text { Gently undulating calcareous plain with reddish-brown } \\
\text { calcareous sandy clay loam ( } \mathrm{Gc} 1.12 \text { ) }\end{array}$ & $\begin{array}{l}\text { Very sparse Acacia kempeana F. Muell. and A. victoriae } \\
\text { Benth. over Enneapogon spp. and Tripogon loliiformis (F. } \\
\text { Muell.) C.E. Hubbard. }\end{array}$ \\
\hline $\begin{array}{l}\text { Cottonbush flat } \\
\text { (CBF) }\end{array}$ & $\begin{array}{l}\text { Flat alluvial plain with scalded texture contrast soil, } \\
\text { reddish-brown sandy loam over clay loam (Db. 3.53). }\end{array}$ & $\begin{array}{l}\text { Very sparse Maireana aphylla (R. Br.) P.G. Wilson and } \\
\text { Cassia spp. with Sida spp., Enteropogon acicularis (Lindl.) } \\
\text { Lazar and Tripogon lolifformis. }\end{array}$ \\
\hline \multirow[t]{2}{*}{$\begin{array}{l}\text { Open woodland } \\
\text { (OWG, OWP) }\end{array}$} & $\begin{array}{l}\text { OWG: Alluvial plain with gradational soil, dark reddish- } \\
\text { brown sandy loam over sandy clay loam (Gn } 2.43 \text { ). }\end{array}$ & $\begin{array}{l}\text { OWG: Very sparse Cassia and Eremophila spp. over Ennea- } \\
\text { pogon polyphyllus (Domin.) N.T. Burb., Aristida contorta } \\
\text { F. Muell. and Enteropogon acicularis. }\end{array}$ \\
\hline & $\begin{array}{l}\text { OWP: Gentle slope with shallow uniform soil, reddish-brown } \\
\text { sandy loam (Uc 1.21). }\end{array}$ & $\begin{array}{l}\text { OWP: Very sparse Acacia kempeana and Cassia spp. over } \\
\text { Aristida contorta and Enneapogon polyphyllus. }\end{array}$ \\
\hline $\begin{array}{l}\text { Perennial grassland } \\
\text { (PGR) }\end{array}$ & $\begin{array}{l}\text { Alluvial plain with uniform soil, reddish-brown clay loam } \\
\text { (Uf 6.12). }\end{array}$ & $\begin{array}{l}\text { Very sparse Eremophila spp. and Acacia aneura F. Muell. ex } \\
\text { Benth. over mid-dense Enteropogon acicularis and Eulalia } \\
\text { fulva (R. Br.) Kuntze. }\end{array}$ \\
\hline
\end{tabular}

species were collected, dried and weighed, and their proportional moisture content was calculated. Summaries of these data were used by operators making their estimates during the main experiment.

Sub-shrubs such as Sclerolaena spp. were included in the tests but larger shrubs were not. Seven operators undertook all tests, with one exception in which there were 6 operators, and the time taken for the various tasks was recorded.

\section{Comparative Yield}

Detailed descriptions of the method are provided in Haydock and Shaw (1975) and Tothill et al. (1978). In summary, there were 3 stages. Operators selected five $1-\mathrm{m}^{2}$ reference standards by consensus, to represent an equal-interval scale from least to highest dry matter yield, after clipping and weighing vegetation from numerous quadrats to gauge their approximate yields. Next, each operator selected $1001-\mathrm{m}^{2}$ quadrats on a stepped-out grid, and rated them according to the reference standards on a 17-point scale of 1 , $1.25,1.5$ up to 5 . The grid spacing depended on the size and shape of the site, but resulted in an even distribution of quadrats over the whole site. Finally, twelve $1-\mathrm{m}^{2}$ quadrats were selected by 2 or 3 members of the group to represent the range from low to high yield, and all members independently rated them on the 17-point scale. The quadrats were clipped, dried, and weighed to establish a calibration scale for each operator.

Alternative procedures were also followed at some sites. At CBF, an eroded site with obvious spatial heterogeneity in vegetation distribution, all members of the group independently rated a fixed set of 100 quadrats as well as their own individually selected set, in order to investigate the differences among operators independently of vegetation distribution. At $O W G$, a relatively uniform site, the same test was performed but with only 50 fixed quadrats, due to time limitations. At OWP, operators increased their number of individually selected quadrats from 100 to 200 , to more fully investigate how many quadrats might ultimately be necessary to minimize differences among operators.

\section{Dry-weight-rank}

Operators also estimated which species occupied first, second, and third place in terms of dry weight for each quadrat. These rankings were to be converted to percent composition by a set of multipliers provided by Jones and Hargreaves (1979). Recommended procedures for treating equal-ranked species, less than 3 species, and species which consistently formed a high proportion of the biomass were followed: details of the method are available in ' $t$ Mannetje and Haydock (1963), Tothill et al. (1978) and Jones and Hargreaves (1979).

\section{Data Analysis}

\section{Comparative Yield}

All data were initially analysed with the MSDOS version of the BOTANAL program (Hargreaves and Kerr 1978, revised 1981), modified to allow processing of selected quadrat increments. Four different curves were fitted to each operator's calibration data from each site, using the 4.04B version of GENSTAT (copyright Lawes Agricultural Trust: Rothamsted Experimental Station 1984). These were linear regressions of untransformed, $\log$ transformed and square root transformed data, and quadrat regression of untransformed data. The regressions were weighted according to the numbers of quadrats in each yield rank at 100 quadrats, and they were calculated for the individually chosen quadrats only. The different calibration regressions were compared according to their percentage of variation accounted for, and according to the number of negative yield estimates obtained for low-yield quadrats. The term "yield estimates" is used throughout to denote estimates derived from individuals' calibration regressions from each site.

To determine whether the differences among operators were minimized after a certain number of quadrats, the coefficient of variation (CV) of all individuals' yield estimates was calculated at $20,40,60,80$, and 100 quadrats. CVs were based on variation from the mean of all individuals. For OWP and the OWG fixed quadrats, CVs were calculated up to 200 and 50 quadrats, respectively. The increments in quadrat numbers were achieved by random selection from the rows of quadrats on the sampling grid.

The degree of significant difference among operators was investigated in greater detail on a more limited number of quadrat intervals: yield estimates of all operators for the first $\mathbf{4 0}$ and $\mathbf{6 0}$ quadrats were subjected to analysis of variance (ANOVA) after log transformation to normalize skewed distributions of data.

ANOVA was not appropriate for the fixed sets of quadrats because the data were not randomized. Instead, a regression equation was calculated for the individual quadrat yield estimates of every possible observer-pair combination, and analysis of covariance (Zar 1984, p. 300-2) was used to test whether the slopes and elevations of the pair-wise regression combinations were different. Yield estimates were log transformed to normalize the data distribution, before the analyses.

\section{Dry-Weight-Rank}

DWR data were also analysed with the MSDOS version of the BOTANAL Program (Hargreaves and Kerr 1978, revised 1981), modified to allow processing of selected quadrat increments. Following the same progression of data analysis outlined for CY, differences among the species composition estimates of operators 


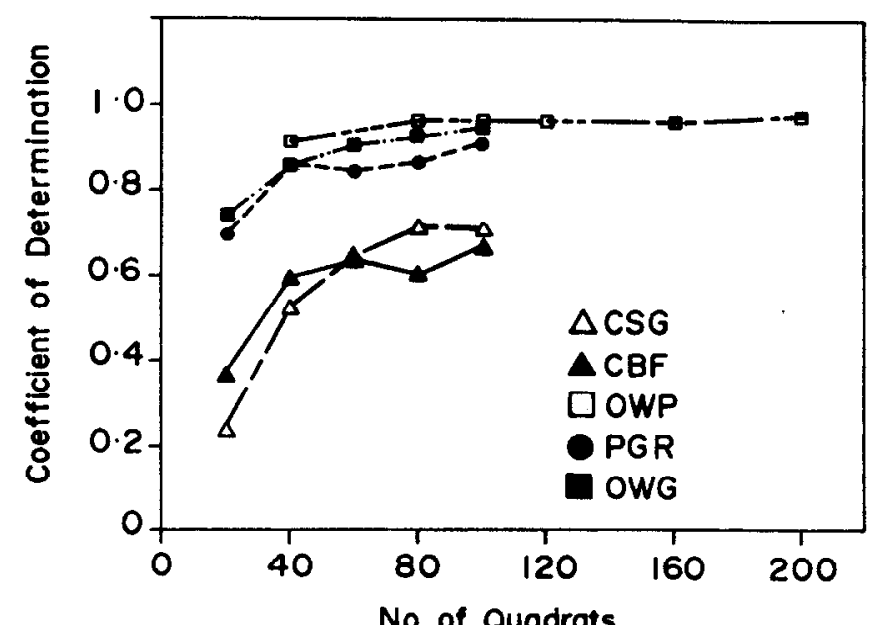

No of Quadrats

Fig. 1. Effect of increasing numbers of quadrats on the differences among species composition estimates of 7 operators, as indicated by group mean coefficients of determination $\left(\mathrm{r}^{2}\right)$ on calcareous shrubby grassland (CSG), cottonbush flat (CBF), open woodland with shallow uniform soil $(O W P)$, open woodland with gradational soll (OWG), and perennial grassland (PGR).

were compared at the same increments in quadrat number. Linear regression of arcsine transformed, percent composition data from every possible observer-pair combination was used to produce a matrix of coefficients of determination $\left(r^{2}\right)$, from which means of $r^{2}$ were derived. Three different estimates of species composition were included: 1 calculated with unweighted multipliers and 2 calculated with weighted multipliers (see Jones and Hargreaves (1979) for a discussion of weighting), where the weighting factors were yield estimates derived from the linear untransformed and square root transformed calibration regressions for each site. These procedures were followed for both the individually selected quadrats and the fixed sites of quadrats.

\section{Results}

Data in the Tables are presented in the same order that the sites were visited.

\section{Comparative Yield}

\section{Effect of Calibration Regression}

The log transformed regression accounted for the least variation in the calibration data (41.4 to 67.6\%), and the quadratic regression produced negative estimates of yield on low-yield quadrats, for most operators at 3 of the 5 sites. Consequently, only the linear untransformed ( 50.5 to $82.2 \%$ variance accounted for) and square root transformed (47.0 to $81.0 \%$ ) regressions were used in all later analyses. In general, if the regression accounted for $50 \%$ or more of the variance in the data, it was regarded as satisfactory. An exception was made for the $47 \%$ value, since all others obtained from the linear square root transformed regression were above 57\%. Any negative yield values were set to zero.

\section{Effect of Linear Square Root Transformation}

Use of the transformation reduced the variability among operators at some sites but not at others, in the various data analyses that were performed. The conclusions to be drawn from the data were the same, with or without the use of the transformation, and so only the analyses of linear untransformed data are reported here.

\section{Effect of Increasing Numbers of Quadrats}

Uitterences among operators had not stabilized after 100 quadrats and the CVs were generally large (Table 2). However, between
Table 2. Effect of increasing numbers of quadrats on the mean yield estimates $\left(\varepsilon / \mathrm{m}^{2}\right)$ of 7 operators. Coefficients of variation $(\%)$ are given in brackets.

\begin{tabular}{lccccc}
\hline \hline \multirow{2}{*}{$\begin{array}{l}\text { No. of } \\
\text { quadrats }\end{array}$} & \multicolumn{5}{c}{ Range Type } \\
\cline { 2 - 6 } & CSG & CBF & OWP & PGR & OWG \\
\hline & \multicolumn{5}{c}{ OW/ } \\
\hline 40 & $47.7(26.5)$ & $17.6(19.7)$ & - & $169.7(22.9)$ & $67.3(23.6)$ \\
40 & $44.1(28.9)$ & $16.4(12.6)$ & $17.1(23.2)$ & $166.7(13.2)$ & $67.3(26.7)$ \\
60 & $40.7(27.0)$ & $17.0(21.7)$ & $16.6(20.9)$ & $161.9(6.9)$ & $70.6(22.1)$ \\
80 & $43.9(36.6)$ & $16.7(28.6)$ & $16.7(19.5)$ & $174.0(9.0)$ & $68.7(22.1)$ \\
100 & $50.8(34.5)$ & $16.3(25.5)$ & $16.6(18.7)$ & $182.6(9.3)$ & $67.9(20.1)$ \\
120 & - & - & $16.9(19.8)$ & - & - \\
160 & - & - & $16.6(23.1)$ & - & - \\
200 & - & - & $16.7(21.2)$ & - & - \\
\hline
\end{tabular}

40 and 60 quadrats, differences decreased in all sites except CBF and so the nature of the differences was examined at these intervals by ANOVA (Table 3). It was clear that while overall estimates had approached one another more closely at 60 quadrats (Table 2), the variation within the 60 quadrats was generally greater than at $\mathbf{4 0}$ quadrats (Table 3 ). The degree of significant difference actually increased.

Table 3. F values' for ANOVA of 7 operators' yield estimates, at 40 and 60 quadrats.

\begin{tabular}{lrrrcc}
\hline \hline $\begin{array}{l}\text { No. of } \\
\text { quadrats }\end{array}$ & \multicolumn{6}{c}{ Range Type } \\
\cline { 2 - 6 } & CSG & CBF & OWP & PGR & OWG \\
\hline 40 & 8.82 & 6.89 & 10.38 & 3.25 & 7.38 \\
60 & 17.50 & 17.03 & 17.09 & 3.71 & 8.44 \\
\hline
\end{tabular}

Levels of significance at $p<0.01$ and 0.001 are:

40 quadrats -2.86 and 3.86

60 quadrats -2.85 and 3.83

\section{Individually Selected vs. Fixed Quadrats}

When all operators estimated yield from the same quadrats, the variability among individuals' estimates of OWG was considerably less at $\mathbf{4 0}$ quadrats and above, than if the operators had selected their own quadrats (Table 4). Unexpectedly, the reverse was the case at the strongly patterned CBF site.

Table 4. Comparison of mean yield estimates $\left(\mathrm{s} / \mathrm{m}^{2}\right)$ of 7 (CBF) or 6 (OWG) operators for individually-selected and fixed quadrats. Coeflcients of variation (\%) are given in brackets.

\begin{tabular}{lcccc}
\hline \hline & \multicolumn{4}{c}{ Range Type } \\
\cline { 2 - 5 } $\begin{array}{l}\text { No. of } \\
\text { quadrats }\end{array}$ & $\begin{array}{c}\text { CBF } \\
\text { (individual) }\end{array}$ & $\begin{array}{c}\text { CBF } \\
\text { (fixed) }\end{array}$ & $\begin{array}{c}\text { OWG } \\
\text { (individual) }\end{array}$ & $\begin{array}{c}\text { OWG } \\
\text { (fixed) }\end{array}$ \\
\hline & & & $-\mathrm{g} / \mathrm{m}^{2}$ & $($ c.v.\%) \\
20 & $17.6(19.7)$ & $24.0(21.5)$ & $68.8(24.4)$ & $54.0(25.2)$ \\
40 & $16.4(12.6)$ & $19.0(29.5)$ & $68.5(28.2)$ & $63.0(18.8)$ \\
50 & - & - & $70.0(29.1)$ & $64.7(17.3)$ \\
60 & $17.0(21.7)$ & $18.0(33.2)$ & - & - \\
80 & $16.7(28.6)$ & $16.7(36.0)$ & - & - \\
100 & $16.3(25.5)$ & $17.6(34.6)$ & - & - \\
\hline
\end{tabular}

Did fixed quadrats confer an advantage? Differences among operators were significant with fixed quadrats: where slopes were not significantly different, elevations were (Table 5). Although Tables 3 and 5 are not directly comparable, the inferences from both are the same: regardless of the way quadrats were chosen, individuals' estimates of yield differed significantly. 
Table 5. F values 1 for covariance analydis of 7 (CBF) or 6 (OWG) operators' yield eatimates at 60 or 50 fixed quadrats respectively.

\begin{tabular}{lrcccc}
\hline & \multicolumn{3}{c}{ CBF } & & \multicolumn{2}{c}{ OWG } \\
\cline { 2 - 3 } \cline { 5 - 6 } Operator & Slope & Elevation & & Slope & Elevation \\
\hline 1 & 6.40 & 32.59 & & 19.07 & 13.74 \\
2 & 7.09 & 36.26 & & 13.60 & 9.75 \\
3 & 10.09 & 48.03 & & - & - \\
4 & 2.34 & 30.15 & & 39.62 & 20.39 \\
5 & 2.53 & 34.16 & & 55.85 & 19.44 \\
6 & 6.50 & 34.64 & & 21.49 & 15.50 \\
7 & 10.91 & 31.42 & & 33.54 & 10.85 \\
Mean & 6.55 & 35.32 & & 30.53 & 14.95 \\
\hline
\end{tabular}

'Levels of significance at $p<0.05,0.01$ and 0.001 are:

CBF $-2.24,3.08$ and 4.22

OWG $-2.41,3.40$ and 4.79

Dry-Weight-Rank

Effect of Weighting

Unweighted multipliers were satisfactory. Weighted multipliers did not maker operators' estimates of species composition more alike, with the exception of the "untransformed" weighting of PGR data. The improvement for PGR was marginal; at some other sites, weighted multipliers conferred a marginal disadvantage. Only the analyses with unweighted data are presented here.

\section{Effect of Increasing Numbers of Quadrats}

Correlation among operators' estimates increased markedly between 20 and $\mathbf{4 0}$ quadrats. Subsequent increases were less with every 20-quadrat interval, so that improvements were only small from 60 to 100 quadrats (Fig. 1).

\section{Individually Selected vs. Fixed Quadrats}

When all operators assessed the same quadrats, species composition estimates were more closely correlated than they were when quadrats were selected by each individual (Fig. 2 and Table 6). The correlation was particularly improved at $\mathrm{CBF}$, the site where vegetation distribution was clearly patterned.

Time

Excluding CSG, where operators were least experienced, the mean time to assess 100 quadrats for both yield and species composition was 2 hours 15 mins (from Table 7). The time taken by the
Table 7. Mean time taken \pm SE (min) for comparative yield and dryweight-rank procedures, by 7 operators $(\mathrm{DF}=6)$.

\begin{tabular}{lcccccc}
\hline \hline & \multicolumn{5}{c}{ Range Type } \\
\cline { 2 - 6 } & CSG & CBF & OWP & PGR & OWG \\
\hline & & & & min \pm SE & \\
\hline $\begin{array}{l}\text { Individual's } \\
100 \text { quadrats }\end{array}$ & $206 \pm 18$ & $136 \pm 9$ & $130 \pm 8$ & $134 \pm 8$ & $141 \pm 6$ \\
$\begin{array}{l}\text { Individual's cali- } \\
\text { bration quadrats }\end{array}$ & $29 \pm 2$ & $12 \pm 1$ & $13 \pm 2$ & $11 \pm 1$ & $12 \pm 2$ \\
\hline
\end{tabular}

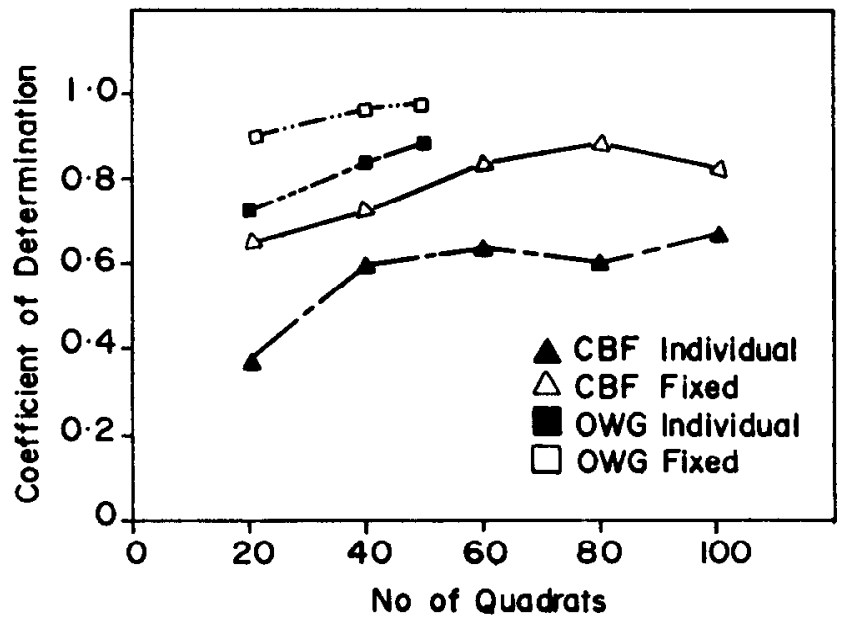

Fi3. 2. Comparison of species composition estimates of 7 (CBF) or 6 (OWG)operators for individually selected or fixed quadrats, as indicated by group mean coefficients of determination $\left(\mathrm{r}^{2}\right)$. CBF is cottonbush flat; OWG, open woodland with gradational soil.

group to select yield standards ranged from 1 to 2 hours, and to select and later harvest the calibration quadrats was 30 mins. Once again excluding CSG, the mean time for individuals to assess the calibration quadrats was 12 mins. Thus, the process of standard

Table 6. Estimates of percentage species composition in CBF from 60 individually-selected or fixed quadrats. Group mean coeficients of determination $\left(r^{2}\right)$ are 0.64 and 0.84 respectively.

\begin{tabular}{|c|c|c|c|c|c|c|c|}
\hline \multirow[b]{2}{*}{ Species } & \multicolumn{7}{|c|}{ Operator } \\
\hline & 1 & 2 & 3 & 4 & 5 & 6 & 7 \\
\hline \multirow{2}{*}{\multicolumn{8}{|c|}{$\begin{array}{l}\text { (a) Individually-selected } \\
\text { Chloris scariosa F. Muell. }\end{array}$}} \\
\hline & 4 & 6 & 6 & 10 & 5 & 10 & 6 \\
\hline Enteropogon acicularis & 20 & 31 & 28 & 13 & 20 & 21 & 11 \\
\hline Fimbristylis dichotoma (L.) Vahl & 8 & 2 & 1 & 10 & 6 & 5 & 9 \\
\hline Sclerolaena divaricata (R. Br.) Domin & 2 & 2 & 4 & 5 & 9 & $\mathbf{0}$ & 3 \\
\hline & 8 & 4 & 7 & 8 & 4 & 8 & 3 \\
\hline Sida sp. & 25 & 27 & 30 & 23 & 22 & 28 & 36 \\
\hline Tripogon loliiformis & 22 & 15 & 12 & 24 & 20 & 15 & 20 \\
\hline Other species (each contributing $<5 \%$ ) & 11 & 13 & 12 & 7 & 14 & 13 & 12 \\
\hline \multicolumn{8}{|l|}{ (b) Fixed } \\
\hline Chloris scariosa & 9 & 9 & 8 & 10 & 9 & 8 & 10 \\
\hline Enteropogon acicularis & 21 & 23 & 17 & 18 & 20 & 17 & 20 \\
\hline Fimbristylis dichotoma & 1 & 1 & 2 & 7 & 4 & 8 & 6 \\
\hline Sclerolaena divaricata & 9 & 7 & 6 & 8 & 7 & 6 & 7 \\
\hline Sclerolaena lanicuspis & 16 & 19 & 18 & 13 & 16 & 18 & 18 \\
\hline Sida sp. & 29 & 25 & 29 & 22 & 21 & 27 & 24 \\
\hline Tripogon loliiformis & 4 & 7 & 7 & 9 & 11 & 7 & 5 \\
\hline Other species & 11 & 9 & 13 & 13 & 12 & 9 & 10 \\
\hline
\end{tabular}


selection and calibration took on average about 2 hours, giving an overall time of 4 hours $\mathbf{1 5}$ mins for the complete procedure.

\section{Discussion}

Pasture in arid rangelands is very patchy distributed and yield in particular can fluctuate a great deal in a short time. Short-term variation in yield is such that accurate estimates for monitoring purposes are not worth the time spent attaining them. It is sufficient for trained operators to obtain reasonably consistent estimates of both yield and long-term change in yield.

The CY method tested in this study did not meet these requirements within the time constraints of a monitoring program, but it is possible to modify the procedure, to achieve useful estimates (Friedel and Bastin 1988). The CY method is worth adapting because it is compatible with DWR, which we recommend over other techniques for estimating species composition.

As tested here, CY had several weaknesses. Differences among operators were generally large (Table 2) and significant (Table 3), so that only the grossest changes in yield could be confidently determined if different operators were responsible for assessments on different occasions. We might expect that a series of assessments over time would be subject to less error if undertaken by the same operator throughout, but this was not tested.

Differences among operators' yield estimates were not simply due to sampling differences in a spatially variable environment; variation among operators' estimates remained high when the same quadrats were assessed by everyone (Table 4). It would be relatively simple to correct for the disparity if operators consistently over- or under-estimated yield in comparison with one another, but they did not. Both the slopes and the elevations of pair-wise regressions of observers' estimates were different (Table 5), indicating that some observers were over-estimating high yields and under-estimating low yields, in comparison with others.

Assessing 100 quadrats for both yield and composition took an average of 2 hours 15 mins (Table 7, excluding CSG), after initial experience with the methods. The mean $\mathrm{CV}$ for yield estimates was $18.4 \%$ (from Table 2, excluding CSG). In a comparable test, Friedel and Shaw (1987) reported that point-based aerial cover and composition could be estimated in a similar time, with a mean CV for cover estimates of only $10 \%$ for 6 operators, and that an acceptable level of accuracy could be achieved by a single operator in $\mathbf{4 0}$ to $\mathbf{7 0}$ minutes. To match this latter time, the number of quadrats would have to be reduced to about 50 , and CVs would remain high. The disadvantages of aerial cover estimates are that they are not matched by satisfactory cover-based estimates of species composition (Friedel and Shaw 1987), and that cover is less useful than yield for assessing forage quantity.

The process of CY standard selection and calibration was too time-consuming to be of use in a monitoring program and we suggest the efficiency of the method can be improved by using photographic standards, which are used for calibration as well (Friedel and Bastin 1988). A wide variety of photographs, representing different vegetation structure, distribution, yield, composition, and phenology can be substituted for the 5 reference standards. Since photographic standards can be carried by operators for constant checking against quadrats in the field, it is likely that precision of estimates will improve.

The dry-weight-rank method is recommended for determining species composition firstly because operators could apply the ranking scheme consistently; increasing the number of sampling units (quadrats in this case) increased the similarity among operators' estimates (Fig. 1). By contrast, Friedel and Shaw (1987) found that, when a point-based measure of cover and composition was used, differences among operators became more entrenched with extra sampling units, and so estimates of composition diverged. Secondly, correlations of operators' estimates from the dry-weight-rank technique were high (Fig. 1) after 60 quadrats in about 80 mins: that is, within a realistic period of time for monitoring. However, in our opinion, the species compositions which gave rise to an $r^{2}$ value of 0.64 (Table 6) would be too different from one another to be acceptable for monitoring, whereas those which gave $r^{2}=0.84$ would be satisfactory. The options for increasing the similarity of operators' estimates include increasing the number of quadrats (and the time taken), more training, and the use of fixed quadrats.

The improvement in $r^{2}$ values when all operators assessed the same quadrats (Fig. 2, Table 6) indicates that differences among individuals' estimates were considerably influenced by spatial pattern. We suggest that monitoring a set of fixed quadrats would reduce the effect of spatial variability, but this advantage may be offset by the extra time spent on relocating quadrats in difficult terrain.

Like Gillen and Smith (1986), we found that weighted multipliers did not improve composition estimates, and that operator training was important. P.E. Novelly, D. Despain, E.L. Smith and W.E. Frost (pers. comm.) showed that weighted multipliers were useful in some of their desert grasslands, so the decision to use weighting will depend on pasture type.

DWR is easy to use and can be combined with recording the frequency of less common species. It has the advantage that, being dry-weight based, the estimates are directly related to forage quantity, which cover-based estimates are not. It is also potentially very useful in combination with the comparative yield technique, if the efficiency of the latter is improved as we propose.

Griffin and Bastin (1988) have devised a program for a handheld computer which will collect and check data from a modified comparative yield and an unweighted dry-weight-rank technique, and will calculate estimates of pasture yield, composition and frequency in the field. This package of methods and analytical tools enables data to be interpreted immediately in the field, which we believe is an important prerequisite of an effective monitoring system.

\section{Literature Cited}

Barnes, D.L., J.J. Odendaal, and B.H. Beukea. 1982. Use of the dry-weightrank method of botanical analysis in the Eastern Transvaal highveld. Proc. Grassl. Soc. So. Afr. 17:79-82.

Bonham, C.D. 1976. An optimum sampling strategy for plant species frequencies. J. Range Manage. 29:160-165.

Friedel, M.H., and G.N. Bastin. 1988. Photographic standards for estimating yield in arid rangelands. Aust. Range. J.

Friedel, M.H., and K. Shaw. 1987. Evaluation of methods for monitoring sparse patterned vegetation in arid rangelands I. Herbage. J. Environ. Manage. 25:297-308.

Gillen, R.L., and E.L. Smith. 1986. Evaluation of the dry-weight-rank method for determining species composition in tallgrass prairie. J. Range Manage. 39:283-285.

Grimn, G.F., and G.N. Bastin. 1988. Hand-held-computer program for field-capture of herbage yield and composition data using a modified dry-weight-rank and yield estimate method. CABIOS.

Harereaves, J.N.G., and J.D. Kerr. 1981. BOTANAL-A comprehensive sampling and computing procedure for estimating pasture yield and composition. II. Computational package. CSIRO Australia Divn. Tropical Crops and Pastures, Brisbane, Queensland, Tropical Agron. Tech. Mem. 9, 1978.

Haydock, K.P., and N.H. Shaw. 1975. The comparative yield method for estimating dry matter yield of pasture. Aust. J. Exp. Agr. Anim. Husb. 15:663-670.

Hyder, D.N., and F.A. Sneva. 1960. Bitterlich's plotless method for sampling basal ground cover of bunchgrasses. J. Range Manage. 13:6-9.

Jones, R.M., and J.N.G. Harereaves. 1979. Improvements to the dryweight-rank method for measuring botanical composition. Grass and Forage Sci. 34:181-189.

Kelly, R.D., and L. MeNelll. 1980. Tests of two methods for determining herbaceous yield and botanical composition. Proc. Grassl. Soc. So. Afr. 15:167-171.

't Mannetje, L., and K.P. Haydock. 1963. The dry-weight-rank method for the botanical analysis of pasture. J. Brit. Grassl. Soc. 18:268-275.

Northcote, K.H.1971. A factual key for the recognition of Australian soils. 3rd Ed. Rellim Technical Publications, Glenside, So. Australia. 
Poissonet, P.S., J.A. Poissonet, M.P. Godron, and G.A. Lons. 1973. A comparison of sampling methods in dense herbaceous pasture. J. Range Manage. 26:65-67.

Reese, G.A., R.L. Bayn, and N.E. West. 1980. Evaluation of doublesampling estimators of subalpine herbage production J. Range Manage. 33:300-306.

Sandland, R.L., J.C. Alexander, and X.P. Haydock. 1982. A statistical assessment of the dry-weight-rank method of pasture sampling. Grass and Forage Sci. 37:263-272.

Santillan, R.A., W.R. Ocumpaugh, and G.0. Mott. 1979. Estimating forage yield with a disk meter. Agron. J. 71:71-74.

Strauss, D., and D.L. Neal. 1983. Biases in the step-point method on bunchgrass ranges. J. Range Manage. 36:623-626.
Tothill, J.C., J.N.G. Hargreaves, and R.M. Jones. 1978. BOTANAL-A comprehensive sampling and computing procedure for estimating pasture yield and composition. I. Field sampling. CSIRO Australia Divn. Tropical Crops and Pastures, Brisbane, Queensland, Tropical Agron. Tech. Mem. 8.

van Dyne, G.M., W.G. Vozel, and H.C. Fisser. 1963. Influence of small plot size and shape on range herbage production estimates. Ecology 44:746-759.

Walker, B.H. 1970. An evaluation of eight methods of botanical analysis on grassland in Rhodesia. J. Applied Ecol. 7:403-416.

Zar, J.H. 1984. Biostatistical analysis. Prentice-Hall, Inc., Englewood Cliffs, New Jersey. 